\title{
Benefits of Outdoor Pursuits: From a Health Perspective
}

Anwar MN1 and Muhammad $\mathrm{A}^{2}$

${ }^{1}$ Communication and Media Studies Department, Khushal Khan Khattak University Karak, Pakistan

${ }^{2}$ Physical Education in GDC, Sabir Abad, Karak, Pakistan

*Corresponding author: Anwar MN, Communication and Media Studies Department, Khushal Khan Khattak University Karak, Pakistan, Tel: 0927291027; E-mail: naseem.anwar@kkkuk.edu.pk

Received date: November 05, 2015; Accepted date: December 05, 2015; Published date: December 10, 2015

Copyright: @ 2015 Anwar, et al. This is an open-access article distributed under the terms of the Creative Commons Attribution License, which permits unrestricted use, distribution, and reproduction in any medium, provided the original author and source are credited.

\begin{abstract}
This paper inspects the determinants of recreational practices amongst respondents using outside of their homes. The term Recreation is derived from a Latin word "re-career" means the way of recharging or regenerating of self while Health is the quality of life to live long and serve best throughout the life suture. The study explains the sports ideology especially in respect of wholesome health. The information collected will provide guidance to the development of policy in the areas of health, sport, education, transport and the environment all of which have important roles to play in getting Pakistanis' people and children more active more often. The study aimed at that freely possessed natural spaces are an ideal to human sustenance and that Parks and outdoor recreation spots are exhale of the community and summit is product. A reliable likert scale of 10 items with 5 choices has been used for responses on benefits of outdoor pursuits, on health perspective was constructed.
\end{abstract}

\section{Objectives}

The purpose of this study was!

- To evoke the idea that freely possessed natural spaces are an ideal to sustenance for human health and wellbeing

- To inculcate that Parks and outdoor recreation spots are exhale of the community and summit is product

The focus of the study was to find out the answers of the following questions.

- How do the recreation and its occurrence affect the chance of pleasing in outdoor recreational activities?

- Is there a link between achievement of career and positive health through outdoor recreation?

Keywords: Environment; Mental health; Hyperactivity disorder; Hospitalization

\section{Introduction}

The Alberta Centre for Well Being finds that - "the concept of wellbeing or optimal health involves a delicate balance among physical, emotional, spiritual, intellectual and social health".

Leisure is defined as free or unobligated time that does not involve work or performing other life sustaining functions, in which leisure is seen as a means of promoting self-growth and helping others. According to Edginton and Chen, leisure provides an optimal opportunity for seeking new experiences, gaining knowledge, skills, attitudes, and values.

Physical activities are beneficial for periods. Fuller in 1705 stated: "if some of the benefits accruing from regular Physical activity could be procured by any one medicine, then nothing in the world would be held in more esteem than that medicine". A physical activity is a tool for reduction of weight or girls and boys by expenditure of fat and is a treatment of childhood obesity.

The study of Maller et al. and Godbey, showed that features of outdoor recreation not only promote the physical health but it healthier the emotions also. The venues of outdoor recreation offer wholesome development of health with the superlative means.

Research suggests that physical activities in outdoors develop mental health and psychological nourishment, a study has confirmed that girls have deem and compensations than boys. Parks and outdoor recreation spots are respire of the community and discloser (meeting) is artifact [1]. It is evident proof that nature is for health. A study has shown that life in olive milieu has absolute relation with indicators of health as stress and level of physical involvement; this relationship is stronger of less educated people [2]. Because of insofar time the benefit of outdoor recreation regarding health is the chance of minimization of loading and anguish from germs effecting health and in living abroad of home are desk bounded. Instead of it people with optimum stress suffer from seasonal as well as cardio-vascular infirmities [3]. Circulation, the journal of the American Heart Association has found that mental stress causes deficient flow of blood towards heart and is a factor of coronary diseases. The outlay of time in nature deficits stresses, aggressions and violence [4].

Copious research has shown that illness (injuries) rehabilitate rapidly when a person has direct linkage to nature [5]. By outdoor pursuits prevention is done and those activities are good which have regular involvement in a person life. A study has shown that brisk walking three hours in week or an hour every day minimize $30-40 \%$ cardiovascular diseases in women.

Anxiety, negative moods and worries declination come on paying time in parks. More and Hull [6,7], less stressed the natural activities are joyful and tendency for to efficient the movements, people of all ages remain agile in recreational activities than their house led commitments [8]. Children having more time in outdoors remain 
healthy, has no fatty diseases, the more inclination of physical activities the more pronation to illness [9].

Various studies have shown that in preschool age children has durable relation with physical activities [10], a study has observed that a symptom which does not heal with medicine may abruptly heals with outdoor physical involvements [11].

Many researchers have studied that. Attention Deficit Hyperactivity Disorder(ADHD) can lessen by outdoors, green spaces may be intercalate in screen watching in leisure, effects of ADHD are contracted utilization of senses, attention problems and illness of health. Research has proven that people have direct deal with outdoors remain active than else ones [10].

Physical activities and outdoors shorts the social threats relating sexual health and pregnancy, a study conducted by US researchers has estimated that juvenile have more participation in outdoors remain sexually flexible in life than non-involvers. WHO can vest the sexual strategies. The easy approach to parks the more utilization will be in outdoors. The immediacy of parks enables the youth inhabitants to reap the beneficiaries of physical activities. Physical activities and outdoors improves health and act as constituent of optimum health Gains [12]. Physical fitness comes through outdoors is important in nursing and halting glitches of health, restricts the limits in performance to health.

\section{Methodology of the Study}

\section{Population}

All the stake holders comprising of three pacts I.e. Doctors, professors, institutions heads and players of the KPK province will be population of the study. It will be very much impossible to collect data from all the stake holders therefor the population will be delimited to District karak and will take 100 respondents of the whole population.

\section{Sample and sample size}

The convenient type of sample was used and took 25 respondents from each segment of the population.

\section{Tool of data collection}

The researcher will use closed form of questionnaire for attainment of responses from the respondents. The questionnaire was of Likert nature having five choices (strongly agrees, agree undecided, disagree, and strongly disagree). The mass of these options will give as below.

Strongly agree $=1$ Agree $=2$ Strongly disagree $=3$ Disagree $=4$ Undecided $=5$

The description of the questionnaire contained of 10 questions. The questionnaire was developed itself and the questionnaire was valid and reliable through expert's opinions. The questionnaire comprised of the areas like the role of outdoor pursuits in healthy life, alertness during normal life through sports, economic health of a nation through play, reservation of manpower, money and time sports, coordination among societies and one of the basic that sports and outdoor pursuits produces leaders and thinkers in this hectic era.

\section{Mode of data collection}

For gripping the most worthwhile conclusions the researcher will personally meet the respondents and will explain the confusion if he has.

\section{Analysis of data}

The data was collected through questionnaire and analyzed with appropriate statistical techniques.

\section{Results}

Most of the respondents' opined that outdoor sports and recreation is a tool intermingled in the present busy scenario, without participation in it human cannot survive. Beside of its $99 \%$ population argued that the co-ordination among various body systems, decisions empowerment, planning entertainment is highly nourished through sports and athletics life.

Our bodies are our temples, and we must learn to protect and preserve it, the protection is only made through sports. There are countless benefits of sports and outdoor recreation like healthy life, alertness, removal of disorders, obesity, promotion of economy, physical fitness, less hospitalization, can only be abducted through sports and outdoor involvement. Success in life and social contests require more than just being fit, which demands motor skills, speed and power, the only domain for this accomplishment is sports and athletic life.

\section{Conclusion}

The one third age declination in aerobic capacity can only be restricted through long aerobic activities. Sports participation can dramatically boost up the children self-esteem and cognitive powers. Like a famous quote as "sound mind as in a sound body". The founder of Pakistan Quaid-e-Azam Muhammad Ali Jinnah stated in address in Islamia college as" sports produce people of healthy bodies and healthy minds, therefore the leading nations of world largely take part in it".

\section{References}

1. Cranz G (1982) The Politics of Park Design. MIT Press, Cambridge.

2. De-Vries S, Verheij R, Groenewegen H, Spreeuwenberg P (2003) Natural Environments-Healthy Environments? An Exploratory Analysis of the Relationship between Green Space and Health. Environment and Planning 35: 1717-1731.

3. Bell R, Summerson J, Spangler J, Konen J (1998) Body Fat, Fat Distribution, and Psychosocial Factors among Patients with Type 2 Diabetes Mellitus. Behavioral Medicine 24: 138-143.

4. Kaplan S (1995) The Restorative Benefits of Nature-Toward an Integrative Framework. Journal of Environmental Psychology 15: 169-182.

5. Frumkin H (2001) Beyond Toxicity Human Health and the Natural Environment. American Journal of Preventive Medicine 20: 234-240.

6. More T, Payne B (1978) Affective Responses to Natural Areas near Cities. Journal of Leisure Research 10: 7-12.

7. Hull R, Michael S (1995) Nature-Based Recreation, Mood Change and Stress Restoration. Leisure Sciences 17: 1-14.

8. Chow H (2007) Physically Active Leisure among Older AdultsMeasurement, Comparison and Impact. VDM Verlag Publishers, Germany.

9. Milnes S (2008) Penn State Web Based learning Units. 
Citation: Anwar MN, Muhammad A (2015) Benefits of Outdoor Pursuits: From a Health Perspective. Arts Social Sci J 6: 143. doi: 10.4172/2151-6200.1000143

Page 3 of 3

10. Sallis J, Prochaska J, Taylor W (2000) A Review of Correlate of Physical Activity of Children and Adolescents. Medicine and Science in Sports and Exercise 32: 963-975.

11. Kuo F, Taylor A (2004) A Potential Natural Treatment for AttentionDeficit/Hyperactivity Disorder-Evidence from a National Study. American Journal of Public Health 94: 1580-1586.
12. Pate R, Pratt M, Blair S, Haskell W, Macera C, et al. (1995) Physical activity and public health-A recommendation from the Centers for Disease Control and Prevention and the American College of Sports Medicine. Journal of the American Medical Association 273: 402-407. 